\title{
EL PAPEL DE INTERNET HACIA UN PLANEAMIENTO TERRITORIAL MÁS PARTICIPATIVO.
}

\author{
Auribel Villa Avendaño ${ }^{1}$ \\ Departament d'Urbanisme i Ordenació del Territori \\ Universitat Politècnica de Catalunya.
}

Remisión artículo: 07-01-2008

Remisión definitiva: 15-02-2008

Palabras Clave: planeamiento territorial, internet, participación.

Resumen: El presente artículo resalta la importancia de sacar el mayor provecho de los recursos digitales, en específico el uso del Internet, como parte imprescindible del proceso de adecuación de los instrumentos de planeamiento a uno de los nuevos paradigmas que se han venido gestando a partir del inicio del siglo XXI; el de propiciar una mayor y mejor participación ciudadana en las políticas territoriales.

Para ello se dibuja un panorama general sobre el uso del Internet y las nuevas tecnologías de comunicación y su repercusión en la gestión pública.

Finalmente se analizan algunas páginas de Internet destinadas a la difusión de una nueva generación de planes territoriales en Italia, Francia y Cataluña, con el objetivo de identificar cuáles son las características específicas de Internet, entender la lógica de este nuevo medio de comunicación y representación y sentar las bases que nos lleven a explotar todo su potencial.

\section{1. “Introducción."}

A nadie escapa que el inicio del siglo XXI ha traído consigo una revolución en todos los sentidos; en el ámbito social, cultural, económico y tecnológico, entre muchos otros.

Estos cambios tienen repercusión en la morfología de las ciudades; lo que ha originando que la planificación urbana, tal y como había sido concebida hasta ahora, haya quedado rebasada por los nuevos modelos de ciudad que están emergiendo.

Frente a nueva realidad que se presenta cada vez más compleja, los instrumentos hasta ahora utilizados por el planeamiento parecen simplistas y reduccionistas.

Ante esta situación, la academia a respondido con amplias discusiones y constantes reflexiones en torno a la renovación del planeamiento y la construcción de nuevos paradigmas que ayuden a construir unos instrumentos de planeación que estén preparados para asumir el reto de ser capaces de ajustarse a las nuevas demandas que exige una sociedad en constante cambio.

Sin embargo, a pesar de que la discusión teórica está bastante trabajada, en la práctica falta aún mucho camino por recorrer, pues si bien existe en muchos países una "nueva generación"

\footnotetext{
${ }^{1}$ Auribel Villa Avendaño auribel.villa@gmail.com
} 
de planes en los que se percibe la intención de incorporar muchas de las inquietudes desprendidas de las discusiones teóricas, no acaban de dar respuestas del todo satisfactorias a estas demandas.

La pregunta obligada es ¿qué esta sucediendo? Por qué si se tienen las ideas tan claras parece costar tanto trabajo llevarlas a su concreción.

Considero que en buena parte se debe a que existe un desfase entre el fin que se busca y la manera de conseguirlo. Por ejemplo; hasta ahora no hemos sabido aprovechar en todo su potencial los medios de representación que las nuevas tecnologías ponen a nuestra disposición, nos hemos limitado a digitalizar los viejos instrumentos, pero los planos en esencia siguen siendo los mismos, o muy similares, simplemente se hacen utilizando otro medio para dibujarlos.

Pareciera que no hemos asumido que estamos ante unos medios completamente distintos; la informática nos ofrece muchas más posibilidades de lo que nos ofrecía el dibujo a mano. Obedece a una lógica distinta, que está además íntimamente ligada y relacionada con los cambios que se esperan del urbanismo; después de todo, esta revolución, se debe en gran medida a los avances tecnológicos de las últimas décadas.

Para poder hacer frente a esta tercera revolución urbana, como la llama Ascher, 2004, los cambios deben ser de fondo, no pueden restringirse a su contenido, deberían pasar por un replanteamiento en la forma de utilizar los mecanismos de representación. Si verdaderamente queremos consolidar un nuevo urbanismo de dispositivos que elaboren, discutan, negocien y hagan avanzar los planes; que sea a la vez reflexivo, precavido, participativo, flexible, heterogéneo, estilísticamente abierto y multisensorial (Ascher, 2004), será imprescindible incorporar las nuevas tecnologías, pues sólo con el apoyo de los nuevos recursos que tenemos a mano podremos empezar a dar respuesta a las inquietudes que ya han sido planteadas en forma muy clara desde la teoría.

La adecuada explotación de los recursos informáticos es imprescindible y debe estar íntimamente ligada en la construcción de los nuevos instrumentos de planeamiento.

\section{2. "La relevancia de las nuevas tecnologías de comunicación en el contexto actual"}

El contexto y el período en que vivimos se caracterizan por la tendencia a una sociedad compleja, a veces contradictoria, imprevisible, incierta e insegura (Belil, 2003). La comunidad ya no es un bloque único y homogéneo, sino, que, por el contrario, hablamos de un cuerpo demográfico cada vez más diferenciado, con grupos sociales y subgrupos con identidades bien definidas. Los intereses, las inquietudes y las demandas, por consiguiente también se multiplican; ante este panorama, las nuevas tecnologías de comunicación ofrecen una amplia gama de posibilidades que pueden ayudar a dar cabida a muchas de estas voces que de otra forma sería muy difícil de escuchar.

La importancia de las nuevas tecnologías de comunicación en los procesos de planeamiento y de gestión es ampliamente reconocido, pues proporciona a todos aquellos involucrados en ellos herramientas para la toma de decisiones y la creación de consensos, que utilizadas correctamente, son capaces de involucrar e incluso comprometer a los ciudadanos en estos procesos. Intelcities, 2005. 
Las nuevas tecnologías de comunicación pueden garantizar una mayor transparencia en la gestión gubernamental, una mejor difusión de la información pública, una participación ciudadana más activa, entre otras cuestiones; aspectos que, bien empleados podrían llevar a generar una mayor confianza en los gobiernos.

No es gratuito que la utilización de medios como el Internet estén cada vez difundidos entre las instancias gubernamentales; según datos referidos en Porras 2003, en junio del 2000 los Estados de 176 países contaban con una página web.

\section{3. "Internet y la construcción de procesos participativos"}

En una sociedad en donde la individualidad, la libertad y el derecho a elegir se han vuelto los bienes más preciados; en la que los grupos sociales a pesar de ser cada vez más pequeños, son al mismo tiempo cada vez más numerosos y más activos de lo que eran antes (Belil, 2003); el Internet adquiere un papel relevante, pues es una herramienta, que bien utilizada, puede ser de gran utilidad en la construcción de proceso participativos más efectivos e incluyentes.

\section{1 “La gestión pública en la era del Internet”}

De acuerdo a la clasificación hecha por Porras, 2003 existen 3 niveles de incidencia del Internet en la gestión pública.

El Modelo Gerencial, cuyo principal objetivo es hacer más eficientes los servicios y los trámites gestionados por el gobierno. Este nivel no implica cambios sustantivos en la forma en que el Estado normalmente gestiona estas actividades; el papel de Internet se reduce a ser un instrumento que eficiente y haga menos costosa su operatividad, pero no implica modificaciones ni en la orientación, ni en la forma, ni en el contenido de las políticas. No hay un intercambio, los flujos son siempre unidireccionales.

El Modelo Consultivo, en el que Internet y el resto de las tecnologías digitales abren nuevas posibilidades para que los organismos del Estado recopilen, analicen y procesen la información remitida por los ciudadanos. En este nivel se consigue una mayor legitimidad al lograr que los actores involucrados se sientan parte del proceso de toma de decisiones. Este modelo tampoco plantea transformaciones sustanciales, pues no concibe mecanismos para que el intercambio de información entre el Estado y sus interlocutores sea estable y permanente.

El Modelo Participativo, es el único que supone una transformación profunda de la concepción y funcionamiento de la gobernabilidad a partir de la incorporación del Internet. Su principal objetivo es crear estructuras de coordinación y cooperación horizontal en las que sean posibles intercambios más complejos; en que la información fluya no sólo entre el estado y el ciudadano, sino entre redes de ciudadanos.

Actualmente la tendencia de los gobiernos sigue siendo inclinarse por el modelo gerencial, prima el temor y la desconfianza de que el Internet propicie fenómenos de participación ciudadana tales que la sociedad se vuelva difícilmente gobernable. 
La participación es un valor que reconoce el derecho de los ciudadanos a generar procesos que les permitan tomar plena conciencia de sus decisiones y a participar en ellas a partir de un conocimiento profundo de la realidad, permitiendo el acceso colectivo a la información. Maffrand, 2001.

No se pretende que el Internet venga a reemplazar los mecanismos de participación ciudadana tradicionales, sino de reforzarlos y ofrecer nuevas formas y medios que sean más acordes con los tiempos actuales. El Internet puede ser un medio para que los ciudadanos se impliquen de manera mucho más activa en los procesos de construcción de los planes; pues permite que la información se vuelva mucho más accesible; ya no es necesario, por ejemplo, desplazarse a un sitio concreto en una hora determinada para poder ser escuchado.

Evidentemente el Internet no es una panacea, puede ayudar a procesos más participativos siempre y cuando se estructure de manera adecuada y sea ese el fin que se busca. Se corre el riesgo también de que Internet sea una herramienta para el elitismo democrático (Davoudi, 2003) y se vuelva una manera de legitimar decisiones ya tomadas por un grupo restringido de políticos y "expertos" en la materia, o bien limitarse la creación de consensos para limar asperezas en temas puntuales que susciten polémica.

El verdadero reto está en construir una democracia participativa en la que los ciudadanos tengan una rol mucho más activo y se les permita involucrarse en la construcción de los instrumentos y de las políticas que los regirán.

En este esquema no basta con informar al ciudadano de las decisiones que se toman desde el gobierno, sino de buscar mecanismos de retroalimentación y de discusión que permitan que las observaciones y las peticiones ciudadanas sean efectivamente tomadas en cuenta.

\section{3 "Pasos hacia una participación más efectiva"}

Es precisamente esta forma de participación activa en que la ciudadanía juega un papel importante en la formulación de las políticas públicas uno de los elementos estratégicos para la generación de la gobernabilidad de una ciudad (Belil, 2003).

Este modelo, si bien es más acorde a las demandas de la sociedad, que cada vez con más frecuencia exige ser parte de los procesos y renuncia a un papel pasivo en el que tan sólo se le informa de las decisiones tomadas; es más difícil lograr que efectivamente se lleve a buen término. Es necesario en primer lugar eliminar, o al menos reducir en la medida de lo posible, la división que se da entre los profesionales expertos y el ciudadano común.

El primer paso para gestar la participación es un proceso de difusión y de información que permita transmitir a los ciudadanos los conocimientos mínimos necesarios para que puedan aportar ideas y propuestas fundamentadas.

Para ello se vuelve importante entender la lógica de este nuevo medio de comunicación y explotar al máximo los recursos que ofrece.

El usuario medio, por ejemplo, seguramente no dedicará un tiempo demasiado largo a una consulta, a menos que se logre atrae su atención; por lo que la información debe ser accesible, 
con una interfaz sencilla y manejable, las ligas deben ser claras para poder acceder de forma fácil a la información.

Es bueno que los documentos se puedan descargar, pero primero hay que seducir al usuario, que se interese y que con una primera ojeada a la página cuente con las herramientas para entender mejor los documentos que va a descargar.

Internet ofrece la posibilidad de una transferencia masiva de la información, pero además de eso ofrece muchas otras posibilidades, como la interactividad, que pueden hacer que la información resulte más interesante para el usuario y que el mensaje llegue de mejor manera, para así sentar las bases de una comunicación eficiente.

En cualquier caso, no hay que subestimar el hecho de que en Internet se maneja tanta información que es fácil que el internauta se sature, así que hay que buscar mecanismos de atraer su atención.

Pero la importancia del internet puede ir mucho más allá. En la medida en que los documentos difundidos por internet estén bien trabajados, pueden llegar a tener una relevancia que sobrepase los límites del propio plan para el cual fueron concebidos. Pueden servir para retroalimentar futuras discusiones en torno a problemas similares; no necesariamente en el ámbito geográfico al que corresponden, pues hay procesos que se dan de maneras muy similares en distintas latitudes del mundo; se puede aprender mucho de las inquietudes expresadas por la comunidad y los mecanismos empleados para responder adecuadamente a esas demandas.

\section{4. "Análisis comparativo de tres casos de estudio."}

Muchas administraciones han tomado conciencia de la importancia de Internet, prueba de ello es que muchos de los nuevos planes territoriales que se están generando tienen su propia página en Internet tal es el caso del Piano Territoriale di Coordinamento Della Provincia di Bologna (www.planum.net/ptcpbologna/indexContent.html), del Schèma de Coherence Territoriale de Lyon (www.scot-agglolyon.fr/) y del Departamento de Política Territorial y Obras Públicas de la Generalitat de Catalunya (www.gencat.net/ptop)

La sola existencia de estos recursos en línea implica ya un compromiso de difundir los planes y sentar las bases para la discusión y la participación de sectores más amplios de la población. En la página del Departamento de Política Territorial y Obras Públicas de la Generalitat de Cataluña, destaca el esfuerzo por reunir en un solo sitio todos los planes de nueva generación; cada uno de los planes que se pretende aprobar tiene ligas a los documentos oficiales relevantes de su proceso de redacción.

Aunque esta página tiene un indiscutible mérito como medio de difusión de estos nuevos planes, puede considerarse que sigue siendo un tanto elitista, en el sentido de que los documentos disponibles están bastante especializados. De tal suerte que, aún si teóricamente se está poniendo al alcance de la sociedad en general la información necesaria para que puedan participar en los procesos de consulta ciudadana, el carácter de estos documentos los vuelve de difícil acceso a las personas ajenas a la disciplina urbanística.

En este sentido, la página del SCoT de Lyon está mucho más orientada a una efectiva construcción de procesos participativos más incluyentes, pues los documentos disponibles están elaborados para llegar a un público más amplio, pues son en su gran mayoría 
documentos sintéticos, claros, accesibles y de fácil comprensión, lo que sin duda contribuirá a que el proceso de participación ciudadana sea mucho más sólido. Aún si por momentos los medios de expresión utilizados parecen casi infantiles, hay detrás una clara intención de que el ciudadano promedio entienda cabalmente la información que se está transmitiendo.

Uno de los documentos mejor logrados son las fichas síntesis en las que se resumen las problemáticas de cada una de las mesas de discusión que se conformaron para la discusión de las temáticas que se consideran más relevantes para la aglomeración; en la Figura 1 puede verse un ejemplo de dichas fichas. En ella se conjugan textos sintéticos con imágenes que ilustran de manera adecuada el tema que se trata. Se resumen los elementos claves del diagnóstico, identificando aquellas preocupaciones que atañen directamente al tema que se está tratando.

Figura 1 Ficha síntesis del tema Atractividad residencial y solidaridad.

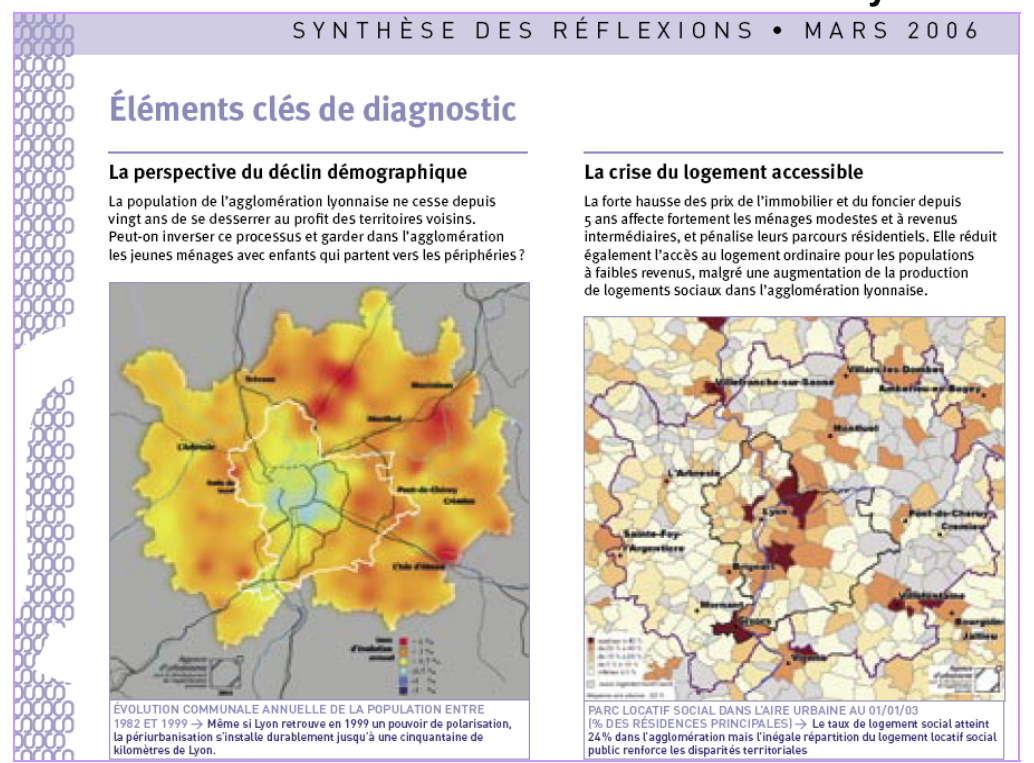

Fuente: Página de Internet del SCoT de Lyon

A pesar de los aciertos que pueden constatarse en estas dos páginas, siguen sin entender del todo la dinámica del Internet y no aprovechan todas sus posibilidades. Esto se hace más evidente si se les compara con la página del PTCP de Bologna, pues se evidencia en varios aspectos que no están concebidos específicamente para su consulta por Internet.

\section{1 “La imagen"}

Una de las características de la sociedad actual y que se hace más evidente en el Internet, es la relevancia de los estímulos visuales; la imagen utilizada por la DGPTOP y el SCoT de Lyon maneja una estética más acorde con un medio impreso, mientras que la página del PTCP de Bologna tiene una mayor presencia en la pantalla de un ordenador.

"Una imagen dice más que mil palabras"; para conseguir atraer la atención del usuario de Internet, es importante hacer un esfuerzo por plasmar las ideas que quieren transmitirse en una 
imagen; un esquema que transmita la mayor cantidad de información y que explique el proyecto desde el primer vistazo.

El esquema en que se sintetiza el PTCP de Bologna como puede verse en al Figura 2, es muy sencillo y sin embargo condensa los elementos a partir de los cuales está conformada la propuesta (los centros, las redes, los elementos de valor natural y las funciones de excelencia) y la interacción que se busca que se genere entre ellos.

Figura 2 Esquema del inicio de la presentación del PTCP de Bologna
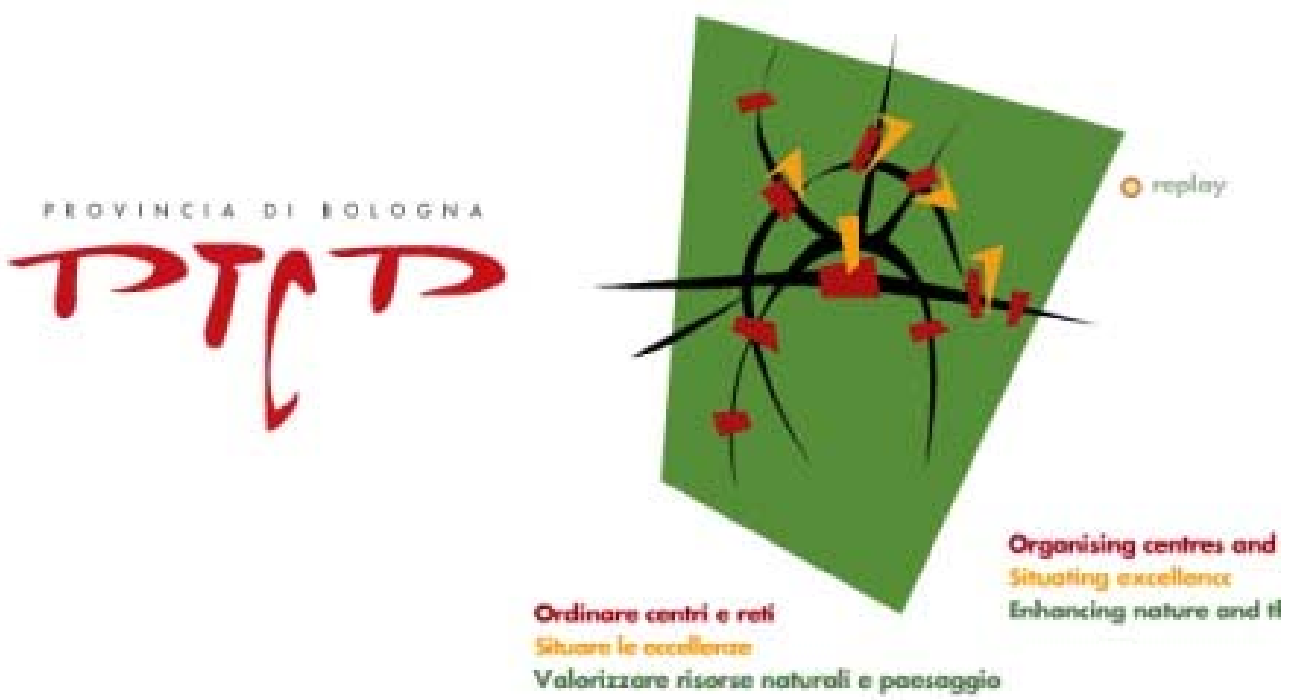

Fuente: Página de Internet del PTCP de Bologna

Pero además de toda la contundencia de esta imagen, se debe agregar una característica que resulta todavía más relevante para su presencia en Internet; la interactividad.

La imagen está concebida para estar en un portal de Internet, por lo que no es un elemento estático, al acceder a la página el esquema se va dibujando poco a poco, con lo que se acaban de redondear algunos conceptos; el cuadro verde, por ejemplo, que en el esquema es una abstracción, inicia siendo la figura de provincia de Bologna. Una vez que termina la animación aparecen en la parte inferior los nombres de los elementos que conforman el plan y al apretar con el cursor sobre ellos la página nos dirige al resumen que corresponde a las actuaciones proyectadas para cada uno de estos elementos.

Es precisamente esta interacción con los elementos dibujados una de las posibilidades que ofrece el Internet y los programas informáticos relacionados, y que lo diferencian de otros medios, específicamente de los medios impresos.

Aprendiendo a manejar esta cualidad se puede hacer que la relación entre el usuario y el plano sea mucho más lúdica, que consiga captar su atención y que lo vaya llevando de la mano por un recorrido del sitio que lo invite a conocer a fondo la información que se le está dando. 


\section{2 "La descarga de los documentos"}

Si bien en las tres páginas existe la posibilidad de acceder a las descargas del documento completo, sólo en el caso del PTCP de Bologna existe la posibilidad de consultar una versión sintética que se puede consultar en línea, sin necesidad de descargar ningún archivo.

\section{3 "El idioma utilizado"}

Mientras que las páginas del SCoT de Lyon y de la DGPTOP sólo manejan el idioma de su región; francés en el caso de Lyon y catalán y español en el caso de la DGPTOP; la página del PTCP de Bologna en cambio está disponible tanto en italiano como en inglés, lo que denota una toma de conciencia del alcance de Internet, que no se limita al ámbito local, sino que puede llegar a todos los rincones del planeta. Al incluir una versión en inglés se incluye a los posibles usuarios no italianos, de tal suerte que se aprovecha la página de Internet no sólo para establecer contacto con los ciudadanos directamente interesados en el plan, sino que va más allá, dándole proyección mundial a la provincia de Bologna. Este puede ser un buen mecanismo desde para atraer inversión extranjera, hasta simplemente para dar a conocer una región a escala global y poder atraer más turistas.

\section{5. "Conclusiones."}

Creo firmemente que en la medida en que seamos capaces de desarrollar las características que nos ofrecen los medios informáticos, más allá de conseguir explotar las cualidades de este medio de representación y de lograr que los documentos generados sean atractivos para el público, seremos capaces de dominar un soporte que nos ayudará a responder a las demandas de flexibilidad, de adaptación a los cambios, etc., que desde la teoría se exige que tengan los nuevos planes.

Quiero concluir con una invitación a buscar la manera de aprovechar al máximo la posibilidad que los nuevos medios nos ofrecen de comunicarnos con distintos sectores de la población, con ciudadanos de todo el mundo pertenecientes a distintas ideologías, con realidades distintas, pero con algo en común. Intentemos pues aprovechar la tecnología para hacernos escuchar y sobre todo para aprender a escuchar. 


\section{Bibliografía.}

Ascher, François. Los nuevos principios del urbanismo. Madrid: Alianza editorial, 2004

Belil, Mireia y Serra, Albert. (2003) La estrategia de la ciudadanía, un ejemplo de promoción de la construcción de proyectos colectivos. En Tarroja, A., Camagni, R. (coords.), Una nueva cultura del territorio. Criterios sociales y ambientales en las políticas y el gobierno del territorio. Barcelona. Ed. Diputació de Barcelona.

Davoudi, Simin. (2003) Participación en la planificación de la sostenibilidad. En Tarroja, A., Camagni, R. (coords.), Una nueva cultura del territorio. Criterios sociales y ambientales en las políticas y el gobierno del territorio. Barcelona. Ed. Diputació de Barcelona.

Maffrand, Graciela. La gestión participativa en la construcción del hábitat residencial. Experiencia con 54 familias dispersas de Villa el Libertador. Invi, 2001, vol. 16, núm. 043.

Porras, José. De Internet, la sociedad red y la política. La emergencia de la Gobernabilidad Digital. Polis, 2003, vol. 1, núm. 004.

Recursos de Internet consultados.

Página del Ptcp Provincia di Bologna

Provincia de Bologna

Recuperada de http://www.planum.net/ptcpbologna/indexContent.html entre los meses de noviembre de 2006 a junio de 2007

Página del Scot de l'agglomération lyonnaise

Sepal Syndicat mixte d'études et de programmation de l'agglomération lyonnaise

Recuperado de http://www.scot-agglolyon.fr/entre los meses de noviembre de 2006 a junio de 2007

Departamento de política territorial y obras públicas de la generalitat de Cataluña

Recuperada de http://www.gencat.net/ptop entre los meses de noviembre de 2006 a junio de 2007 
Architecture, City, and Environment

Arquitectura, Ciudad y Entorno 